\title{
Generación de biogás mediante el proceso de digestión anaerobia, a partir del aprovechamiento de sustratos orgánicos
}

Edwin Antonio Reyes Aguilera ${ }^{1}$

\section{RESUMEN}

El presente artículo tuvo como propósito la conveniencia de abordar una revisión bibliográfica e identificar si existe una o varias teorías con abundante y buen nivel de evidencia aplicable al tema del biogás generado por diferentes sustratos orgánicos. Para la localización de los documentos bibliográficos se utilizaron varias fuentes documentales, se realizó búsqueda en "google académico". Se seleccionaron aquellos documentos que informasen sobre los aspectos formales que debía contener el tema en mención, artículos científicos, tesis doctorales, metodologías utilizadas por diferentes autores, para determinar la selección de la bibliografía encontrada se hizo respecto a la calidad metodológica y si cumplen con los criterios de calidad científica buscada. Se elaboró una estructura lógica que va introduciendo de forma secuencial y razonable la información, de tal manera que el articulo está mejor redactado y permite una fácil lectura y comprensión. Como resultado, se puede decir, que existe diversidad de literatura sobre el tema de estudio sobre el cual se ha recogido información y se puede afirmar que existe información de todo tipo y con diferente nivel científico por lo cual se considera no haber inconvenientes respecto a la literatura existente para el abordaje de una tesis doctoral.

Palabras clave: anaerobia, biogás, biodigestor, biomasa.

Recibido: 24 de julio de 2017

Aceptado: 01 de diciembre de 2017

1 Docente UNAN-Managua/FAREM-Estelí. Estudiante del Doctorado Gestión de la Calidad de la Investigación. UNAN-Managua FAREM-Estelí. Correo electrónico: edwinra11@yahoo.es 


\title{
Generation of biogas through the process of anaerobic digestion, from the use of organic substrates
}

\begin{abstract}
The purpose of this article was the convenience of approaching a bibliographic review and to identify if there is one or several theories with abundant and good level of evidence applicable to the subject of biogas generated by different organic substrates. For the search of the bibliographic documents, several documentary sources were used, the search was done in "google scholar". We selected those documents that were related to the research, scientific articles, doctoral theses, methodologies used by different authors, to determine the selection of the literature found was made regarding the methodological quality and if they fulfill the criteria of scientific quality sought. A logical structure was developed that introduces the information in a sequential and reasonable manner, in such a way that the article is better written and allows easy reading and understanding. As a result, it can be said that there is a diversity of literature on the subject of study on which information has been collected and it can be said that there is information of all kinds and with different scientific levels, which is why there are no disadvantages regarding the existing literature for the approach of a doctoral thesis.
\end{abstract}

Keywords: anaerobic, biogas, biodigester, biomass. 


\section{INTRODUCCIÓN}

En Nicaragua el manejo de los residuos orgánicos ha sido históricamente deficiente, ya que hay situaciones donde estos están cerca de los poblados lo cual afecta a la población causando graves enfermedades respiratorias, al no dársele el tratamiento adecuado a los residuos de origen animal, esto causa graves problemas ambientales por la descomposición química de estos.

Con esta investigación se pretende evaluar el potencial energético generado en diferentes sustratos orgánicos y de esta forma puedan implementarse tecnologías para reducir los despales indiscriminados generados por el alto consumo de leña, así mismo permitirá reducir enfermedades y por ende contribuir a la calidad de vida de las personas. Así como también la presente metodología de caracterización y evaluación servirá de base para futuros investigadores en esta línea de investigación que es esencial en el campo de las energías renovables. La promoción y difusión de las tecnologías para su aprovechamiento son necesarias para que la sociedad se involu $\neg$ cre en el beneficio que tiene el aprovechar los desechos en la producción de energía y en la contribución a la disminución de la contaminación ambiental.

La digestión anaerobia posibilita la degradación de la fracción orgánica biodegradable presente en los residuos sólidos urbanos, transformándola en biogás, con alto contenido en metano y susceptible, por tanto, de aprovechamiento energético y en un residuo final estabilizado, con una alta tasa de destrucción de microorganismos patógenos, que reúne las condiciones para poder ser utilizado como mejorador del suelo. Por ello, la digestión anaerobia presenta un balance energético positivo posibilitando tanto la prevención de la contaminación como la recuperación sostenible de la energía (De Baere, 2000).

El objetivo principal de este artículo es la conveniencia de abordar una revisión e identificar si existe una o varias teorías completamente desarrolladas con abundante y buen nivel de evidencia que se aplique al tema del biogás generado por diferentes sustratos orgánicos; las tecnologías y metodologías utilizadas y si existen teorías o partes de teorías con apoyo empírico moderado o limitado, que sugieran variables potencialmente importantes y que se apliquen al tema de estudio.

\section{MÉTODO}

Para alcanzar el objetivo planteado, se ha utilizado un proceso metodológico dividido en cinco etapas: Definición de los objetivos de la revisión bibliográfica, Búsqueda de información, Criterios de selección bibliográfica, Organización de la información y la redacción del artículo.

\section{Definir los objetivos de la revisión bibliográfica}

La primera etapa fue determinar cuál es el objetivo de la revisión bibliográfica y en función del mismo se redactó un tipo u otro de revisión. En este caso el objetivo tiene carácter descriptivo, las preguntas formuladas fueron del tipo ¿qué se sabe de tema de generación de biogás a partir de diferentes sustratos orgánicos? ¿Qué tecnologías se aplican para la generación de biogás? ¿Cómo se realizan las fases del proceso de digestión anaeróbico?, Y por lo tanto se realizó una revisión descriptiva.

\section{Búsqueda de información}

Para la localización de los documentos bibliográficos se utilizaron varias fuentes documentales que incluye literatura física en biblioteca de la UNAN MANAGUA/ FAREM ESTELÍ. También se realizó una búsqueda en internet en el buscador "google académico" con los mismos términos. Se usó frases además de palabras únicas. Cuando se identificaron estudios relevantes, se revisó para encontrar otros términos que se utilizaron como palabras clave. Los términos alternativos (sinónimos) para los conceptos o variables también fueron de utilidad como palabras clave. 


\section{Criterios de selección bibliográfica}

Se seleccionaron aquellos documentos que informasen sobre los aspectos formales que debía contener el tema en mención, artículos científicos, tesis doctorales, metodologías utilizadas por diferentes autores. Fue conveniente al abordar la revisión, identificar teorías completamente desarrolladas con abundante y buen nivel de evidencia que se aplique al tema o y si existen teorías o partes de teorías con apoyo empírico moderado o limitado, que sugieran variables potencialmente importantes y que se apliquen a nuestro problema.

Los criterios de selección se encuentran determinados por los objetivos del presente artículo, es decir la o las preguntas a la que trata de responder el artículo. Otro de los aspectos fue determinar la selección de la bibliografía encontrada de acuerdo a su calidad metodológica y el cumplimiento de los criterios de calidad científica buscada. En una primera fase los aspectos considerados fueron: el título, los autores, el resumen y los resultados. Respecto al título se observó si es útil y relevante para el tema, de los autores se identificó la credibilidad o experiencia en el tema, y del resumen se analizó si es correcto y si los resultados son aplicables al tema de estudio. En una segunda fase se procedió a la lectura crítica de los documentos.

\section{Organización de la información}

Se elaboró una estructura lógica que va introduciendo de forma secuencial y razonable la información, de tal manera que se organizó la información, y el artículo está mejor redactado y permite una fácil lectura y comprensión.

La organización de la información permitió que los temas complejos parecieran sencillos y la manera más sencilla de alcanzar la simplicidad se hizo mediante la reducción razonada. En primera se redujo la información eliminando todo aquello que no es esencial mediante un proceso que pasó por segmentar la información básica, a medida que se localizaban más documentos, la información se iba incluyendo en orden de modo que tras haber realizado toda la lectura de la bibliografía y seleccionado la información más relevante se procedió a combinar la información de diferentes fuentes en una estructura de carácter común y se procedió a redactar el artículo.

\section{Redacción del artículo}

Para la redacción del artículo se trató en todo momento que tuviera claridad, es decir con ideas claras. Así mismo que tenga concisión, y se es conciso cuando se usa sólo las palabras indispensables, precisas y significativas para expresar lo que se quiere decir, además se utilizó precisión es decir usando un lenguaje sin términos ambiguos ni expresiones confusas o equívocas; así mismo se redactó con sencillez y naturalidad, usando lenguaje común suponiendo huir de lo enrevesado, lo artificioso, lo barroco y de lo complicado.

\section{RESULTADOS DEL ANÁLISIS}

Los déficits y costos crecientes del abastecimiento de petróleo han impulsado a muchos países a encarar estudios sobre práctica de fuentes de energía que reemplacen los habituales combustibles derivados de sistemas convencionales no renovables cuya extinción está prevista para este siglo. Entre los recursos energéticos renovables, se cuenta con una fuente de energía explotada durante las penurias económicas y energéticas producidas durante y después de la última guerra mundial. Se trata del gas del estiércol, gas de los pantanos o gas de granja, producido por fermentación del estiércol de animales, de la paja y de residuos agrícolas en general. Por su origen biológico se lo conoce mundialmente como biogás, que es una mezcla de gases conteniendo metano (50 a 70\%), anhídrido carbónico (30 a 45\%), hidrógeno (1 a 3\%), oxígeno $(0,5$ a $1 \%)$, gases diversos (1 a 5\%) y vestigios de anhídrido sulfuroso (Lockett, 1997).

A nivel mundial, el uso del biogás es variante, va desde emplearsecomocombustiblepara la cocina,calefacción, electricidad, combustible para los vehículos, hasta utilizarlo como el gas "principal" para ser procesado e 
introducido en gasoductos de gas natural (Dutta \& Rehman, 1997); (EREC, 2009); Otros usos están relacionados con el empleo de éste para hacer metanol y ayudar a prolongar la conservación de frutas y granos por la inhibición del metabolismo de ciertos insectos, hongos y bacterias (Mae-wan, 2008).

Las mayores aplicaciones del biogás se han dado en China, India y Europa. China es de los países pioneros en el uso del biogás. Este país perteneciente al continente Asiático desarrolló un programa que inició en los años setenta con un resultado de más de 7 millones de digestores, aunque sufrió de varias fallas (Boyle, 2004).

El desarrollo de la tecnología para el aprovechamiento del biogás en el mundo está ligado parcialmente con los países que más contribución tienen en cuanto a emisiones de metano). Dicha tecnología tiene el potencial de contribuir a la disminución de las emisiones de gases de efecto invernadero (Han, 2008).

Alemania es actualmente, el líder en el despliegue de la tecnología en biogás. En la última década, el número de plan־tas incrementó de 370 en 1996 a 3891 en el 2008 (Poeschl, Ward, \& Owende, 2010). Lo anterior se dio principalmente debido a la implementación del programa "Renewable Energy Sources Act".

Un país que vive escasez de energía es Ghana, en donde la mayor fuente de combustible proviene de la madera alre $\neg$ dedor del $72 \%$, junto con el aceite crudo y las hidroeléctricas. Este país tiene un potencial técnico para la construcción de 278,000 plantas de biogás, desafortunadamente sólo se han establecido un poco más de 100 plantas (Arthur et al., 2011). Otro uso potencial del biogás en países en desarrollo como Ecuador está dirigido al reemplazo del consumo de GLP (Camilo, Ann, \& Wilkie, 2010).

Anivellatinoamericano, se han construido biodigestores en, Colombia, Perú, Bolivia, México, Nicaragua, Costa Rica. Noobstante, también en Europasehaincrementado su producción anual en niveles importantes, Alemania produjo en el 2009, más de 1,144 millones m3 al año, Inglaterra 463 millones m3, Dinamarca 387 millones m3, siguen Italia, Francia, Grecia, Austria, Bélgica, principalmente con fines de producción de electricidad y calor (Miranda, 2007)

En el contexto Nacional del país se han ejecutado diversos proyectos de producción de biogás en las zonas rurales de Nicaragua, un ejemplo de ello es Asofénix ${ }^{1}$, que en conjunto con productores de comunidades rurales de Teustepe y San José de los Rematesinstalaronenconjuntomásde 500 biodigestores para aprovechar el estiércol de ganado y mejorar las condiciones de vida de las personas y de esta manera reducir un poco la presión ejercida sobre los bosques de la zona (Asofénix, 2008).

\section{Residuos orgánicos biodegradables}

Los desechos agroindustriales comprenden un amplio conjunto de residuos orgánicos biodegradables, los cuales pueden ser clasificados en dos tipos generales: residuos de frutas o plantas y residuos provenientes de animales (estiércoles y purines). Los cambios socioeconómicos de las últimas décadas, orientados a la concentración poblacional en núcleos urbanos establecidos, el desarrollo sectorizado de la industria agroalimentaria así como la intensificación de las actividades de índole agrícola y ganadera, entre otros, han propiciado la gran producción periódica de residuos orgánicos biodegradables, los cuales requieren de un manejo específico para evitar la generación de problemas ambientales que a la postre se reflejan en la salud pública y el deterioro de los ecosistemas naturales. Los desechos generados por el sector primario comprenden los residuos agrícolas, ganaderos y forestales; los desechos generados por el sector secundario incluyen los residuos industriales (agroalimentarios, textiles, curtiembres, residuos del papel, etc.) y finalmente se encuentran los residuos

1 Asofenix: Es una ONG nicaragüense que trabaja con organismos nacionales e internacionales para desarrollar y mejorar la vida en las comunidades rurales con energía renovable. 
producidos por el sector terciario de servicios dentro de los que se tienen dos grandes afluentes como la fracción orgánica de los residuos sólidos urbanos y las aguas residuales domésticas (Klinger, Alexander, \& Marchaim, 1991)

\section{Residuos Ganaderos}

Están formados por la acumulación de deyecciones sólidas y liquidas producidas en las explotaciones ganaderas. El uso eficiente de estos residuos sin que se produzcan daños en el medio, especialmente de los líquidos, esobjetivoprioritariodemuchosinvestigadores (Bernal \& Roig, 1993).

Las características de estos materiales son función de: especie, raza, alimentación del ganado y época del año. Las cantidades que se producen dependen del tipo de explotación, puesto que no serán las mismas las originadas en un establo de vacas que en una granja de aves. Podemos mencionar en la tabla 1, algunos valores medios de producción de materia fresca según el animal explotado.

Tabla1:Producción deresiduos frescosdeexplotaciones ganaderas

\begin{tabular}{ll}
\hline \multicolumn{1}{c}{ Tipo de ganado } & \multicolumn{1}{c}{$\mathbf{~ k g ~ h e c e s / d i a ~}$} \\
\hline Vacuno & $30-50$ \\
Equino & $20-50$ \\
Porcino & $4-8$ \\
Ovino & $4-8$ \\
Aves & $0.1-0.5$ \\
\hline
\end{tabular}

Enlatabla2,figuranalgunas características agronómicas de estos materiales, prestando atención a la materia seca y contenido en los nutrientes mayoritarios. (Alcántara, 1993)

Tabla 2: Composición nutritiva de estiércoles en materia fresca

\begin{tabular}{ccccccc}
\hline $\begin{array}{c}\text { Origen del } \\
\text { estiercol }\end{array}$ & $\begin{array}{c}\text { m.s. } \\
(\%)\end{array}$ & $\begin{array}{c}\mathrm{N} \\
\mathbf{K g} / \mathbf{t}\end{array}$ & $\begin{array}{c}\mathbf{P}_{2} \mathbf{O}_{5} \\
\mathbf{K g} / \mathbf{t}\end{array}$ & $\begin{array}{c}\mathbf{K}_{2} \mathbf{O} \\
\mathbf{K g} / \mathbf{t}\end{array}$ & $\begin{array}{c}\mathbf{M g O} \\
\mathbf{K g} / \mathbf{t}\end{array}$ & $\begin{array}{c}\mathbf{S} \\
\mathbf{K g} / \mathbf{t}\end{array}$ \\
\hline Vacuno & 32 & 7 & 6 & 8 & 4 & -
\end{tabular}

\begin{tabular}{lcccccc} 
Equino & 35 & 14 & 5 & 12 & 3 & 0.9 \\
Porcino & 25 & 5 & 3 & 5 & 1.3 & 1.4 \\
Ovino & 28 & 15 & 16 & 9 & 4.5 & - \\
Aves & 8 & 2 & 0.5 & 3 & 0.4 & - \\
\hline
\end{tabular}

En el sector ganadero la problemática asociada con el manejo efectivo de los residuos generados implica el desarrollo de un tratamiento bioquímico eficiente para permitir el aprovechamiento de los nutrientes que se encuentran presentes en estos residuos (Fan, Chen, Mehta, \& Chen, 1985).

No obstante la dificultad de la gestión de los residuos ganaderos subyace de la separación progresiva de la explotación ganadera y agrícola, de forma tal que la mayoría de las instalaciones ganaderas no poseen una infraestructura territorial suficiente para la reutilización de sus propios residuos (Marchaim, 1992). El aumento de la ganadería estabilizada y la disminución de la superficie agrícola útil, hace equiparable el sector ganadero con la industria de transformación de materias primas agroindustriales en cuanto a la intensa problemática de gestión de los residuos (Hashimoto \& Chen, 1982).

El estiércol bovino es un sustrato complejo, el cual presenta considerables contenidos de materiales orgánicos disueltos y articulados, dentro de los que se incluyen polisacáridos, lípidos, proteínas y ácidos grasos volátiles (AGV), además de un conjunto de compuestos inorgánicos. Este sustrato es reconocido como una excelente base para el desarrollo del proceso de digestión anaeróbica debido que presenta una alta capacidad tamponadora y un gran contenido de nutrientes necesarios para el desarrollo de las poblaciones anaeróbicas (Eastman \& Ferguson, 1981).

\section{Gallinaza}

De todos estos residuos, los avícolas merecen una cierta atención por sus especiales características. Están compuestos por deyecciones de aves de corral junto con el material usado en las camas y cal en pequeña 
proporción (si esta es utilizada sobre el piso para mantener unas condiciones sanitarias permisibles en los corrales). Cada ave, proporciona heces diarias aproximadamente correspondientes al $5 \%$ de su peso corporal (Ramírez, 1983).

Además debemos indicar que este material posee un elevado potencial de generación de energía si se fermenta en condiciones anaerobias con producción de biogás como así lo indican (Echaendia \& Menoyo, 1990). Las gallinazas suelen ser relativamente ricas en nitrógeno y tener una buena relación $\mathrm{C} / \mathrm{N}$ y $\mathrm{C} / \mathrm{P}$. En el caso de no usar cal sobre el suelo de los corrales, o explotaciones avícolas, su pH suele ser acido. En la tabla 3 se señalan las características generales de una gallinaza.

Tabla 3: Características de una gallinaza (Ramírez, 1983)

\begin{tabular}{ll}
\hline Materia seca \% & 79.5 \\
peso especifico $\mathrm{g} / \mathrm{cm}^{3}$ & 0.5 \\
pH $\mathrm{H}^{2} \mathrm{O}$ & $5.0-8.0$ \\
materia orgánica & 80.0 \\
N orgánico & 3.00 \\
$C / N$ & 15.5 \\
$P$ total \% & 1.82 \\
$C / P$ & 25.5 \\
\hline
\end{tabular}

Las diferentes características físicas y químicas de las excretas aviares, le atribuyen cualidades para ser utilizada, ya sea como abono, alimento para animales o producción de biogás siemprey cuando sea transformada o procesada y así garantizar no solo su calidad como subproducto, sino su aporte al bienestar del medio ambiente (Estrada Pareja, 2005).

\section{Restos forestales (Aserrín)}

Comoconsecuenciadelamanufacturaeindustrialización quedan en los aserraderos, carpinterías y obrajes montañas de virutas y aserrines cuya acumulación entraña peligros e inconvenientes, como ser riesgo de incendio, contaminación del aire y proliferación de alimañas. Actualmente estos desechos se queman o entierran o se dejan de lado. Todos estos residuos se podrán colocar en un biorreactor y generar una cantidad de biogás que se puede usar para calefacción, cocción o fuerza motriz, y todo con una materia prima que de otra manera se tiraría. El rendimiento de la producción de biogás es muy bajo ya que de todo la materia orgánica, la madera es la que menos produce biogás pero se compensa debido a que la existencia de los desechos es altísima y gratuita (Hilbert., 2007) .

\section{Residuos de plantas acuáticas}

La posibilidad de uso de residuos de plantas acuáticas, siguen siendo materia orgánica conteniendo importantes cantidades de nutrientes que pudieran ser aprovechables si se incluyen como enmendantes en el sistema sueloplanta.

Son susceptibles de ser empleadas como abonos orgánicos de los suelos si se procede a un proceso de secado apropiado; además suelen descomponerse con relativa rapidez. Su composición en agua es elevada así como el contenido en sales. Si nos referimos a la concentración media de N, P y K, podemos apreciar de los datos recogidos en la tabla siguiente que su contenido en nitrógeno no es nada desdeñable (Parr \& Colacicco, 1987).

Tabla 4: Rango de composición en porcentaje de peso seco de algas (Parr \& Colacicco, 1987)

\begin{tabular}{cccc}
\hline & $\mathbf{N}$ & $\mathbf{P}$ & $\mathbf{K}$ \\
\hline Algas & 1.34 & $0.08-0.17$ & $0.06-0.69$
\end{tabular}

Según (Gao \& Mckinley, 1993) las macroalgas tienen una mayor productividad que las plantas terrestres, y no compiten con ellas por el terreno, además, debe considerarse que las algas se pueden cultivar en zonas marinas o en tierra, obteniéndose varias cosechas al año. Por otra parte, grandes cantidades recalan a las costas y en el caso de las playas arenosas de uso turístico tienen que ser recogidas ya que atentan contra la estética de estos entornos y la gran mayoría se depositan en 
lugares inadecuados con deficiente o sin ningún criterio ambiental, además, en su recogida se pierden grandes cantidades de arena afectando de esta manera, el ecosistema en cuestión.

\section{Digestión anaerobia}

Es un proceso biológico en el que la materia biológica del residuo, en ausencia de oxígeno, se degrada o descompone por la actividad de unos microorganismos específicos transformándose en un gas de un elevado contenido energético o "biogás" y en otros productos que contienen la mayor parte de los componentes minerales y compuestos de difícil degradación que se denomina "lodo" (Garrrido, Flotats, Fernández, \& Palatsi, 2009).

La naturaleza y la composición química del sustrato condicionan la composición cualitativa de la población bacteriana de cada etapa, de manera que se establece un equilibrio fácilmente alterable cuando algún tóxico no permite el desarrollo de alguna de las poblaciones. Mientras que en las fases de hidrólisis-acidogénesis los microorganismos involucrados suelen ser facultativos, para la tercera fase los microorganismos son estrictos, y con tasas máximas de crecimiento del orden de 5 veces menores a las acidogénicas. Esto significa que si las bacterias metanogénicas tienen algún problema para reproducirse y consumir los ácidos, estos se acumularán, empeorando las condiciones para las bacterias metanogénicas, responsables de la producción de metano.

Realmente hay una producción en cadena de diferentes tipos de bacterias. Unas inicialmente producen una hidrólisis del estiércol generando ácidos orgánicos. Otro tipo de bacterias digieren estos ácidos orgánicos a través de una deshidrogenación y acetogenésis dando como resultado ácido acético e hidrógeno. Y finalmente otras bacterias, llamadas metanogénicas, digieren el hidrógeno y el ácido acético para transformarlo en metano, que es el gas más importante del biogás y el que permite la combustión.

\section{Fases del proceso de biodegrabilidad}

El conocimiento y aprovechamiento de los procesos naturales de producción de biogás, a través del desarrollo de tec $\neg$ nologías prácticas, han permitido desarrollar un método probado para la conversión de materia orgánica compleja mediante digestión anaerobia con fines de obtener un gas con un alto poder calorífico.

\section{Hidrolisis}

Según este modelo, la primera fase es la hidrólisis de partículas y moléculas complejas que son hidrolizadas, mediante reacciones de oxidación-reducción, por enzimas extracelulares producidos por los organismos fermentativos. Como resultado se producen compuestos solubles, que serán metabolizados por las bacterias anaerobias en el interior de las células. Los compuestos solubles, básicamente diferentes tipos de oligosacáridos y azúcares, alcoholes, aminoácidos y ácidos grasos, son fermentados por los microorganismos acidogénicos que producen principalmente, ácidos grasos de cadena corta, dióxido de carbono e hidrógeno. Los ácidos de cadena corta son transformados en acético, hidrógeno y dióxido de carbono mediante la acción de los microorganismos acetogénicos (Campos Pozuelo, 2001). La formación de metabolitos ácidos en esta fase produciría un pequeño descenso del $\mathrm{pH}$ del medio (hasta valores de 5,5 aproximadamente) si no existiesen, en la etapa siguiente, otros microorganismos capaces de consumir estos ácidos.

La hidrólisis depende fundamentalmente de la temperatura del proceso, del tiempo de retención hidráulico, de la composición del sustrato (porcentaje de lignina, carbohidratos, proteínas y grasas), del tamaño de partícula, del $\mathrm{pH}$, de la concentración de NH4+ y de la concentración de los productos de la hidrolisis. (Peece, 1983). Esta etapa puede ser el proceso limitante de la velocidad global del proceso sobre todo cuando se tratan residuos con alto contenido en solidos (Pavlostathis \& Giraldo Gómez, 1991). 


\section{Acidogenésis y acetogenésis}

Es la segunda etapa dentro de la degradación, en esta el material orgánico es fermentado por varios organismos, formando así compuestos que pueden ser utilizados primeramente por los microorganismos metanógenos (acético, fórmico, H2), y compuestos orgánicos más reducidos (láctico, etanol, propiónico, butírico) que propiamente deben ser oxidados por las bacterias acetogénicas a pequeños sustratos, que le sean factibles de utilizar a las bacterias metanógenas (Gerardi, 2003). Solo el ácido acético formado da lugar al 70\% del metano formado.

Algunos autores consideran difícil establecer una separación entre las bacterias hidrolíticas y las acidogénicas, ya que son muchos los microorganismos capaces de realizar ambos procesos. Así, además de la hidrólisis, en esta etapa también tiene lugar la fermentación de diversos monómeros. Las bacterias formadoras de ácidos o acidogénicas son bacterias de crecimiento rápido, en comparación con los otros grupos implicados en la digestión anaerobia. Las bacterias implicadas en esta etapa son anaerobias obligadas o facultativas, muy abundantes en la naturaleza y bacterias proteolíticas. Se pueden citar bacterias acidogénicas de los géneros Clostridium, Bacillus, Pseudomonas y Micrococcus (Madigan, Martinko, \& Parker, 1998).

Posterior a la fermentación de $\mathrm{H} 2$ y acetato que son productos que pueden ser metabolizados directamente por organismos metanógenos, llegan otros como valerato, butirato, propionato y algunos aminoácidos que necesitan ser transformados en productos más simples y sencillos, acetato e hidrogeno, por medio de las bacterias acetógenas (Stams, 1994).

En esta etapa, los monómeros liberados anteriormente son degradados mediante reacciones fermentativas, en donde los compuestos orgánicos funcionan como aceptores y donadores de electrones. Los principales productos de esta etapa son ácidos grasos volátiles
(AGV), que funcionan como intermediarios degradativos, como son alcoholes, ácido propiónico, n-butírico, n-valérico, capriónico y láctico. Así como los precursores directos para la formación de metano (CH4), que son el ácido fórmico, metilaminas, ácido acético, metanol, hidrógeno (H2) y CO2. Los monómeros son degradados por Lactobacillus, Escherichia, Staphylococcus, Micrococcus, Bacillus, Pseu $\neg$ domonas, Streptococcus (Mara \& Horan, 2003).

Cuando las hexosas (azúcares de seis carbonos) son con $\neg$ vertidas exclusivamente a acetato, la reacción fermentativa es llamada homoacetogénesis (Muller, 2003). Son bacterias estrictamente anaerobias, los géneros más representativos en digestores anaerobios son $\mathrm{Clos} \neg$ tridium, Acetoanaerobium, Acetobacterium, Acetogenium, Butyribacterium, Paleobacter, Treponema y Halophaga. Existe otro tipo de bacterias acetógenas que se caracterizan por la producción obligada de $\mathrm{H} 2$ y por su participación en la degradación de compuestos aromáticos, se denominan OHPA (Obligate Hydrogen Producing Acetogens): Syntrophomo $\neg$ nas, Syntrophobacter, Syntrophospora y Syntrophus (Drake, Kusel, \& Matthies, 2002).

Las reacciones de deshidrogenación acetogénica dependen de la concentración de hidrógeno existente (Boone \& Xun, 1987), por lo tanto para que la acetogenésis tenga lugar en los digestores anaerobios, es necesario que el hidrógeno generado en la misma sea utilizado y consumido con igual velocidad a la que se produce (bacterias metanógenas utilizadoras de hidrógeno y/o bacterias homoacetogénicas) (Schink B., 1997)

Algunos autores admiten la existencia de otras bacterias, denominadas homoacetogénicas, que pueden crecer autotróficamente con dióxido de carbono e hidrógeno para producir acetato (reacciones de hidrogenación acetogénica) cuando las metanogénicas utilizadoras de $\mathrm{H} 2$, están inhibidas debido a un $\mathrm{pH}$ bajo. Así, se considera que el intercambio de hidrógeno es tan rápido en el digestor que originan diferentes microambientes 
con diferentes presiones de hidrógeno, donde ambas reacciones (acetogénicas y homoacetogénicas) se da conjuntamente (Chynoweth \& Isaacson, 1987).

\section{Metanogenésis}

La metanogénesis es el último paso del proceso de descomposición anaerobia de la materia orgánica. En esta etapa los microorganismos metanogénicos son los responsables de la formación de metano a partir de sustratos monocarbonados o con dos átomos de carbono unidos por un enlace covalente: acetato, $\mathrm{H} 2, \mathrm{CO} 2$, formiato, metanol, y algunas metilaminas. Los organismos metanogénicos se clasifican dentro del dominio Archaea, y, morfológicamente pueden ser bacilos cortos y largos, células en forma de placas y metanógenos filamentosos, tanto Gram positivos como Gram negativos (Madigan, Martinko, \& Parker, 1998).

La clasificación de las archaeas metanogénicas utilizadoras de hidrógeno realizada por (Stafford, 1982) se compone de seis géneros principales: Methanobacterium, Methanosarcina, Methanococcus, Methanobacillus, Methanotrix, Methanospirillum. Las reacciones identificadas en la Figura I.3 para estos microorganismos son:

\section{Conversión de acetato en metano por las archaeas} metanogénicas acetoclásticas: la reacción acetoclástica, cuyos productos finales son metano y dióxido de carbono, es llevada a cabo específicamente por los géneros Methanosarcina y Methanotrix. La molécula de acetato se rompe por descarboxilación y el grupo metilo es reducido a $\mathrm{CH} 4$ y $\mathrm{CO} 2$ sin modificar su estructura y sin afectar a la concentración de $\mathrm{H} 2$ en el gas. Normalmente estos microorganismos controlan el pH del medio por la eliminación del acético y producción de $\mathrm{CO} 2$ que se disuelve formando bicarbonato.

La mayoría de los organismos metanogénicos son capaces de utilizar el H2 como aceptor de electrones, mientras que dos géneros son capaces de utilizar el acetato. A pesar de ello, en ciertos ambientes anaerobios, éste es el principal precursor del metano, considerándose que alrededor del $70 \%$ del metano producido en los reactores anaerobios se forma a partir de acetato (Chynoweth \& Isaacson, 1987), mientras que el restante $30 \%$ proviene del $\mathrm{CO} 2$ y $\mathrm{H} 2$.

2. Formación de metano a partir del $\mathrm{CO} 2$ y $\mathrm{H} 2$ por las archaeas homoacetogénicas: la reacción de formación de metano a partir del dióxido de carbono e hidrógeno, actúa en el control del potencial redox de la fermentación en el digestor, evitando la pérdida de hidrógeno y $\mathrm{CO} 2$ durante el crecimiento sobre compuestos multicarbonados, lo que implica en una mayor eficiencia termodinámica (Zeikus, 1979).

Del metano que se produce el $50 \%$ proviene de ácido acético. Este se origina en un 3\% a 5,3\% de la reducción del $\mathrm{CO} 2$ con $\mathrm{H} 2$ a unos $60 \mathrm{oC}$. Otra parte de acetato que proporciona metano, corresponde a la deshidrogenacion del propionato y butirato en un porcentaje de $23 \%$ a 60 oC (Bunca, 2002).

\section{Bacterias sulfato reductoras}

Además de las bacterias señaladas en la etapa metanogénica, también existen en los digestores anaerobios las bacterias denominadas sulfatos reductores. Estas bacterias, especialmente en presencia de sulfatos, tienen capacidad de reducir sulfatos a sulfuros, o sea utilizan el sulfato como aceptor final de electrones en la cadena respiratoria, actuando la materia orgánica como donador de electrones. Estas bacterias, además de utilizar los ácidos pirúvicos y lácticos para su desarrollo, pueden utilizar el ácido acético e impedir la formación de metano. Por otro lado, el exceso de sulfatos puede provocar una baja producción de metano que, puede estar relacionada con la falta de $\mathrm{H} 2$, más que con la toxicidad del sulfato (Chynoweth D. P., 1996).

\section{Factores que influyen en el proceso metanogénico}

Como se mencionó anteriormente las bacterias son las principales protagonistas en este proceso degradativo, 
pero existen determinados parámetros o factores ambientales que hacen más factible el desarrollo de la digestión. Según (Hilbert., 2007), es importante examinar algunos de los factores importantes que gobiernan el proceso metanogénico. Los microorganismos, especialmente los metanogénicos, son altamente susceptibles a los cambios en las condiciones ambientales.

La producción de biogás en el proceso metanogénico depende de los siguientes parámetros descritos por (Hilbert., 2007):

\section{Tipo de materia prima}

La rapidez y eficiencia del proceso de descomposición de la materia orgánica por medio de la fermentación metanogénicas está condicionada por los siguientes factores (Hilbert., 2007).

Las materias primas fermentables incluyen dentro de un amplio espectro a los excrementos animales y humanos, aguas residuales orgánicas de las industrias (producción de alcohol, procesado de frutas, verduras, lácteos, carnes, alimenticias en general), restos de cosechas y basuras de diferentes tipos, como los efluentes de determinadas industrias químicas.

El proceso microbiológico no solo requiere de fuentes de carbono y nitrógeno, sino que también deben estar presentes en un cierto equilibrio sales minerales (azufre, fósforo, potasio, calcio, magnesio, hierro, manganeso, molibdeno, zinc, cobalto, selenio, tungsteno, níquel y otros menores).

Las sustancias con alto contenido de lignina no son directamente aprovechables y por lo tanto deben someterse a tratamientos previos (cortado, macerado, compostado) a fin de liberar las sustancias factibles de ser transformadas de las incrustaciones de lignina. En lo atinente a estiércoles animales la degradación de cada uno de ellos dependerá fundamentalmente del tipo de animal y la alimentación que hayan recibido los mismos. Los valores tanto de producción como de rendimiento en gas de los estiércoles presentan grandes diferencias entre distintos autores.

\section{Temperatura}

En el desarrollo de cualquier proceso bioquímico, la temperatura es uno de los parámetros ambientales más impor $\neg$ tantes ya que mejora ó inhibe a grupos microbianos específicos, esto debido a que las actividades implican reacciones enzimáticas, donde las enzimas son complejos moleculares sensibles a la temperatura. Otra razón son los diferentes tiempos de activación de los grupos bacterianos durante el curso de la digestión, ya que cada uno de estos grupos, tiene una temperatura óptima en donde se puede estabilizar su tasa de crecimiento celular máximo. En el caso del tratamien $\neg$ to anaerobio de lodos, la temperatura del proceso determina la rapidez y el grado de avance de la digestión anaerobia (Mae-wan, 2008).

La biodigestión anaerobia puede ocurrir en un amplio rango de temperaturas que van desde los $5^{\circ} \mathrm{C}$ hasta los $60^{\circ} \mathrm{C}$. Las bacterias metanogénicas son más sensibles a la temperatura que los demás microorganismos de un biodigestor, debido a que su velocidad de crecimiento es más lenta. El proceso de digestión anaerobio no se ve afectado si la temperatura aumenta en unos pocos grados; sin embargo, un decrecimiento podría retardar la producción de metano, sin perjudicar la actividad de las bacterias acidificantes, lo cual permite una excesiva acumulación de ácidos y una posible falla en el biodigestor. En este sentido, se debe procurar mantener un microclima cálido en el biodigestor para conservar una tasa de producción de biogás alta (Bidlingmaier, 2006); (Osorio, Ciro, \& Gonzalez, 2007).

La temperatura de igual forma afecta de manera directa los procesos que controlan la dimensión del crecimiento microbial, así la velocidad con la que crecen los microorganismos responsables del proceso anaerobio aumenta con la temperatura (Van Lier, Hulsbeek, Stams, \& Lettinga, 1993) definiéndose tres rangos de 
temperaturas para clasificar los sistemas: psicrofílico, por debajo de $20^{\circ} \mathrm{C}$, o a temperatura ambiente; mesofílico, entre $30-40^{\circ} \mathrm{C}$, y termofílico entre $50 \mathrm{y}$ $65^{\circ} \mathrm{C}$. El rango mesofílico es el más utilizado, pese a que el termofílico presenta ciertas ventajas, como la mayor rapidez, la higienización del residuo, eliminación de larvas, semillas de malas hierbas, organismos patógenos, mayor hidrólisis de partículas (Gallert, Bauer, \& Winter, 1998). Sin embargo, el rango termofílico puede ser más inestable, sobre todo por la mayor toxicidad de determinados compuestos a altas temperaturas, como el nitrógeno amoniacal (Hashimoto A. G., 1986); (Gallert et al; 1998); o los ácidos grasos de cadena larga (Hwu \& lettinga, 1997); algunas de las ventajas que presenta el rango termofílico son: fermentación más rápida, eliminación de casi un 100\% de virus y bacterias patógenas, separación solidoliquido más rápidamente y disminución de la viscosidad de la solución.

El régimen termofílico se ha relacionado estrechamente con mayores problemas de estabilidad (Hobson, 1995). Sin embargo otros autores consideran que las plantas termofílicas son tan estables y tan operables como las mesofílicas, presentando, además de las ventajas antes mencionadas, una mayor producción de gas por unidad de sólidos volátiles y una mejora en el postratamiento, ya que el efluente de la digestión termofílica es más fácilmente deshidratable, junto con una menor producción de malos olores (Ahring, Sandberg, \& Angelidaki, 1995); (Krugel, Nemeth, \& Peddie, 1998).

\section{Valor de la acidez (pH)}

Los microorganismos anaerobios necesitan de manera estricta un $\mathrm{pH}$ en torno a la neutralidad para su desarrollo correcto, aunque permiten cierta oscilación (Clark \& Speece, 1989), aunque pueden presentarse problemas si baja por debajo de 6 o sube por encima de 8,3 (Lay, Li, \& Noike, 1997). El pH afecta directamente la actividad enzimática de los microorganismos mediante cambios de estado de los iones de las enzimas como el carboxil y amino; alteración que se presenta en los componentes no ionizables del sistema, como por ejemplo la desnaturalización de la estructura proteica de las enzimas (Clark \& Speece, 1989).

Una vez estabilizado el proceso fermentativo el $\mathrm{pH}$ se mantiene en valores que oscilan entre 6 y 8 , valores de pH por debajo de 5 y por encima de 8 se corre el riesgo de inhibir el proceso de fermentación o incluso detenerlo. Debido a los efectos buffer que producen los compuestos bicarbonato-dióxido de carbono (CO2HCO3) y Amonio -Amoníaco (NH4-NH3) el proceso en sí mismo tiene capacidad de regular diferencias en el $\mathrm{pH}$ del material de entrada.

Los valores de PH puede ser corregida para mantenerlo dentro del rango adecuado para el proceso de fermentación, cuando el $\mathrm{pH}$ es alto se puede sacar frecuentemente una pequeña cantidad de efluente y agregar materia orgánica fresca en la misma cantidad o bien, Cuando el pH es bajo se puede agregar fertilizante, cenizas, agua amoniacal diluida.

\section{Relación DBO Y DQO}

Habitualmente se utiliza la relación DBO/DQO para estimar la biodegrabilidad de un agua residual. La determinación de la DBO y la DQO permite establecer la relación existente de contaminantes y según el resultado, conocer la posibilidad o no de efectuar algún tratamiento para las aguas residuales (Mihelcic \& Zimmerman, 2011). La diferencia más notable es que la DBO representa la cantidad de materia orgánica biodegradable, mientras que la DQO representa ambas, tantola materiabiodegradable comolanobiodegradable.

\section{Demanda Bioquímica de Oxigeno (DBO)}

La demanda bioquímica de oxígeno, DBO, se define como la cantidad de oxígeno usado por los microorganismos no fotosintéticos a una temperatura de $20^{\circ} \mathrm{C}$, para metabolizar los compuestos orgánicos degradables biológicamente. Se ha demostrado que gran parte de los microorganismos metabolizan 
aeróbicamente los sustratos orgánicos, tales como lípidos, azúcares, alcoholes o proteínas, tal que alcanzan un máximo rendimiento de producción celular de $0.4 \mathrm{~g}$ de células en peso seco por gramo de DQO eliminada (Sikes, 1975).

Este valor es de gran importancia ya que se relaciona con la cantidad de energía oxidable en el sustrato el cual es microbiológicamente usable por las células para sus requerimientos de energía y su posterior síntesis. Por otra parte se tiene que el valor obtenido para este parámetro en la planta de tratamiento de aguas residuales industriales de Galicia es de 0,127 (Ortiz \& Aguila, 1997), lo cual se sustenta en el origen industrial de estas, lo que se manifiesta en una menor fracción de compuestos biodegradables presentes en el influente.

La razón técnica de hacer las lecturas de DBO a los cinco días de incubación es porque después de este periodo frecuentemente ocurre la nitrificación. La nitrificación o conversión del nitrógeno orgánico y amoniacal a nitritos y nitratos requiere de oxígeno, por lo que la disminución de oxígeno disuelto o incremento de $\mathrm{DBO}$, ya no se debe a la oxidación del carbono orgánico que es lo que se desea medir en este tipo de prueba.

La razón de hacer la lectura a los cinco días de efectuada la prueba y a una temperatura de $20^{\circ} \mathrm{C}$, se debe a que como esta técnica tiene su origen en Inglaterra, la British Royal Commission of Sewage Disposal, determinó que la temperatura promedio de los ríos de este país es de $18.3^{\circ} \mathrm{C}$ y que el tiempo máximo que duran estas aguas en su trayecto de los ríos hacia el mar, es de cinco días. Como ésta prueba de DBO pretende reproducir estos hechos, se seleccionaron los parámetros de tiempo y temperatura ya mencionados, y que por causas circunstanciales coinciden más o menos con las razones técnicas de efectuar las lecturas en esas condiciones. Aproximadamente entre el 90 y 95\% de la DBO presente en el agua residual es originada por pérdidas de leche o productos lácteos (Valencia \& Ramírez, 2009).

\section{Demanda Química de Oxigeno (DQO)}

La demanda química de oxígeno, DQO, se refiere a la cantidad de oxígeno que se quiere para oxidar completamente por medios químicos los compuestos orgánicos a $\mathrm{CO} 2$ y H2O. En las pruebas de DQO se acelera artificialmente el proceso de biodegradación que hacen los microorganismos, mediante un proceso de biodegradación forzada, utilizando oxidantes químicos y métodos debidamente estandarizados, que tienen por objeto la reproducción de las mediciones, esta prueba es una indicación de la cantidad de nutrientes fácilmente degradables presentes en una muestra, es ideal para aplicarla a residuos que contengan entre otros nutrientes con carbón, como las de industrias o métodos de producción biológicos (Metcalf \& Eddy, 1994).

A continuación se presentan algunos valores de DQO en relación a la concentración de sustrato: $1 \mathrm{~g} / 1 \mathrm{de}$ glucosa posee una DQO de 1,4 g/1 (Henze, 1995), 1g/1 de grasa de cerdo corresponde $2,1 \mathrm{~g} / 1$ de DQO y $1 \mathrm{~g} / 1 \mathrm{de}$ aceite girasol a $2 \mathrm{~g} / \mathrm{l}$ de DQO.

\section{Composición de la materia orgánica}

(Valdivia, 2000), propone para la fermentación los microorganismos metanogénicos requiriendo de suficiente material de carga para que el proceso de digestión no se interrumpa, el porcentaje más adecuado de contenido en sólidos es del 5\% al 10\% lo que indica que la biomasa más adecuada es la de alto contenido en humedad.

Durante la digestión se encuentra que no toda materia prima se digiere, si no que parte se convierte en metano, otra en sedimento y habrá también una porción que no se digiere, esta y otras propiedades básicas de la materia se expresan casi siempre como sigue:

\section{Humedad}

Cantidad de agua existente en la materia a utilizar. Se obtiene al secarse el material a $104^{\circ} \mathrm{C}$, hasta que no 
pierda peso; la diferencia entre el peso inicial y el peso final es equivalente a la humedad que contenía la materia.

\section{Sólidos totales}

Materia orgánica sin humedad, es decir, el peso de la materia seca que queda después del secado como se indicó antes. El sólido total suele ser equivalente al peso en seco (sin embargo, si se secan los materiales al sol, es de suponer que aun contendrán, cerca del $30 \%$ de humedad). El sólido total incluye componentes digeribles o "sólidos volátiles" y residuos no digeribles o "sólidos fijos".

\section{Sólidos volátiles (SV)}

Los sólidos volátiles son considerados como la materia que realmente es transformada por las bacterias. Es el peso de los sólidos orgánicos quemados cuando el material seco se enciende (se calienta unos $538^{\circ} \mathrm{C}$ ).

\section{Sólidos fijos (SF)}

Material que no será transformado durante el proceso y es el peso que queda después del encendido (cenizas), se trata de material biológicamente inerte. Los sólidos fijos son el residuo de los sólidos totales, disueltos o suspendidos, después de llevar una muestra a sequedad durante un tiempo determinado a $550^{\circ} \mathrm{C}$.

\section{Ventajas de la digestión anaerobia}

\section{A-Proceso:}

- Permite el tratamiento de fracciones orgánicas de residuos urbanos de diferentes procedencias (Tchobanoglous, Hilary, \& Vigil, 1997).

- Elevados porcentajes de eliminación de materia volátil (40-60\%) (Vogt, Liu, Kennedy, Vogt, \& Holbein, 2002); (Mata Álvarez, Macé, \& Llabrés, 2000); (De Baere, 2000).

- Elevada destrucción de organismos patógenos y organismos parásitos: también produce la inactivación de algunos virus patógenos (entrerovirus y parcovirus), según el tipo de virus, del proceso de depuración y de la temperatura
(Turner \& Burton, Technology).

- Baja producción y estabilización de lodos (Carreras \& Dorronsoro, 1999);

- Alto grado de estabilización del vertido trabajando con altas velocidades de carga (Lissens, Vandervivere, De Baere, Bley, \& Verstraete, 2001).

- Disminución muy significativa de la relación de alcalinidad, así el proceso aporta alcalinidad para favorecer un proceso posterior de nitrificación, total o parcial (Flotats, Bonmatí, Campos, \& Teira, 2000).

\section{B-Producto final:}

- Baja generación total de sólidos biológicos: el producto final posee características similares al compostproducidoaeróbicamente (Tchobanoglous, Hilary, \& Vigil, 1997). Además, el producto final es inerte y rico en ciertos nutrientes y puede emplearse en agricultura como mejorador de suelo (Nopharatana, Pullammanappallil, \& Clarke, 2003); (Chugh, Chynoweth, Clarke, Pullammanappallil, \& Rudolph, 1999).

- Eliminación de ácidos volátiles (AGV) y otros compuestos fácilmente biodegradables, contribuyen para disminuir la fitoxicidad del residuo final (Flotats, Bonmatí, Campos, \& Teira, 2000).

\section{C-Energía:}

- Alta producción de biogás compuesto fundamentalmente por $\mathrm{CH} 4$ y $\mathrm{CO} 2$

- Obtencióndebiogássusceptibledeaprovechamiento energético y económico (Dorronsoro \& Carreras, 1999).

- Bajo consumo energético: la alta producción de biogás con elevado valor energético reduce significativamente los costes del tratamiento (Milan, y otros, 2001).

- Reducción de la emisión de gases responsables por del efecto invernadero (Massoud \& El-Fadel, 2001). 


\section{Tecnología de Biodigestores}

\section{Concepto}

Es un contenedor cerrado, hermético e impermeable (llamado reactor) dentro del cual se deposita el material orgánico a fermentar en determinada dilución de agua para que se descomponga por microorganismos, produciendo por un lado gas metano y por otros fertilizantes orgánicos ricos en nitrógeno, fosforo y potasio (Valdivia, 2000).

(Contreras L. , 2006) Define un Biodigestor como un contenido hermético, donde se realiza un proceso anaeróbicodedescomposición(procesodefermentación anaeróbica). La materia prima está constituida por materia orgánica, como desechos agrícolas, residuos animales, residuos humanos, etc.; es decir, en el biodigestor tal como indica su nombre sucede una digestión de la materia prima, luego de la cual se obtiene biogás, biol y bioabono aproximadamente en un periodo. Definiendo las siguientes características:

\section{Tipos de biodigestores por su forma}

(Contreras, 2006) Establece cuatro tipos de biodigestores: De cúpula fija, de cúpula móvil, y tipo salchicha. Estos biodigestores tienen la característica principal que son de flujo continuo lo que permite la entrada y salida constante de fluido. A continuación, se describen cada uno de ellos:

\section{De cúpula fija}

Son aquellos armados en una sola estructura que por regla general es hecha en materiales rígidos (concreto, bloques o ladrillos). Debido a la alta presión que pueden alcanzar en su interior y a la constante variación de la misma, se recomienda su construcción en forma de domo, bajo tierra en suelos estables y firmes, y la impermeabilización de la parte interna de la estructura a fin de evitar el escape de líquido y gases. Estos factores hacen obligatorio el uso de mano de obra altamente calificada para su diseño y construcción.

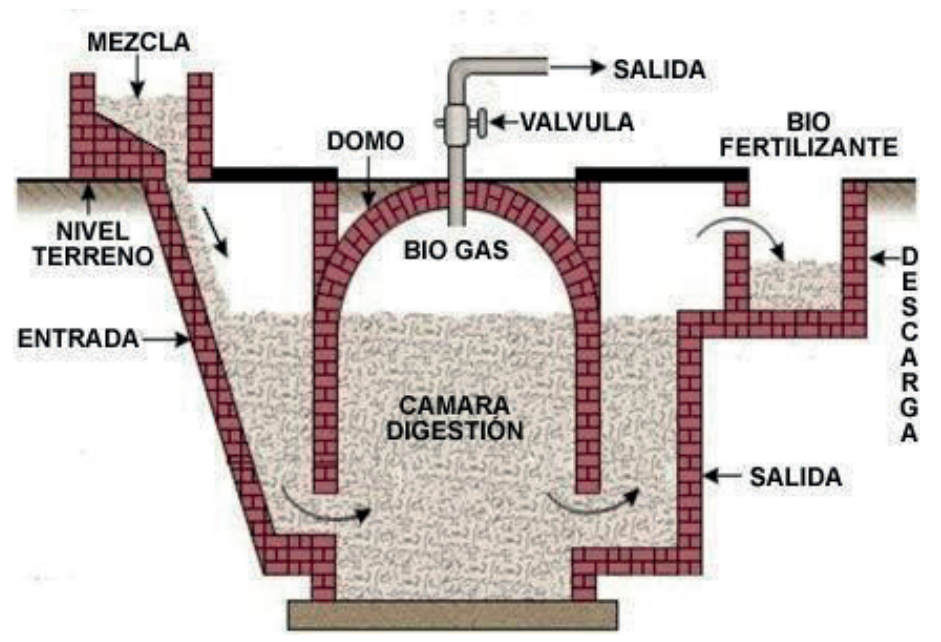

Figura 1: Cámara de digestión con cúpula fija

\section{Biodigestor de cúpula fija o tipo chino}

El modelo de cúpula fija tiene como principal característica que trabaja con presión variable; sus principales desventajas, son que la presión de gas no es constante y que la cúpula debe ser completamente hermética, ello implica cierta complejidad en la construccióny costosadicionalesenimpermeabilizantes. Sin embargo, este modelo presenta la ventaja de que los materiales de construcción son fáciles de adquirir a nivel local, así como la inexistencia de partes metálicas que pueden oxidarse y una larga vida útil si se le da mantenimiento, además de ser una construcción subterránea. (Jarauta, 2005).

Son aquellos armados en una sola estructura que por regla general es hecha en materiales rígidos (concreto, bloques o ladrillos). Debido a la alta presión que pueden alcanzar en su interior y a la constante variación de la misma, se recomienda su construcción en forma de domo, bajo tierra en suelos estables y firmes, y la impermeabilización de la parte interna de la estructura a fin de evitar el escape de líquido y gases. Estos factores hacen obligatorio el uso de mano de obra altamente calificada para su diseño y construcción (Botero \& Preston, 1987). 


\section{De cúpula móvil}

Los biodigestores de este grupo tienen dos estructuras: la primera al igual que en los de estructura sólida fija, va enterrada y hecha en concreto, bloque o ladrillo; la segunda en la mayoría de los casos es una campana metálica que "flota" sobre la primera estructura (Valdivia, 2000).

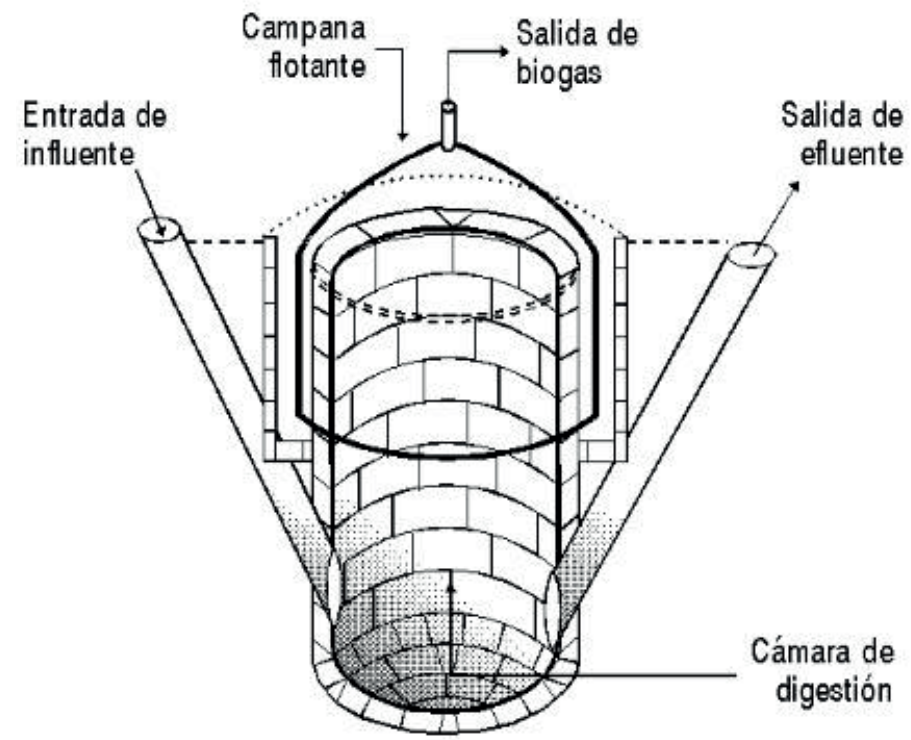

Figura 2: Cámara de digestión con cúpula móvil

Los de régimen semicontinuo se construyen enterrados, se cargan por gravedad una vez al día, en la parte superior flota una campana donde se almacena el gas (Viñas, 1994).Se caracteriza por tener un depósito de gas móvil a manera de campana flotante, esta campana puede flotar en la masa de fermentación o en un anillo de agua. Las ventajas de este tipo de planta son que trabajan a presión constante y se puede determinar la cantidad de gas almacenado por el nivel de la campana; pero tiene como desventaja que está expuesto a la corrosión ya que las campanas son generalmente metálicas. (Contreras, 2006).

\section{Sistemas batch o discontinuo}

Son aquellas que se encargan completamente de una sola vez y son vaciadas por completo después de un tiempo de retención fijado. Dentro de esta categoría la más conocida es la planta Olade Guatemala. El modelo tipo Batch es apropiado para cargar todo tipo de materiales de fermentación, debido a que el tiempo de retención con el que se trabaja es largo.

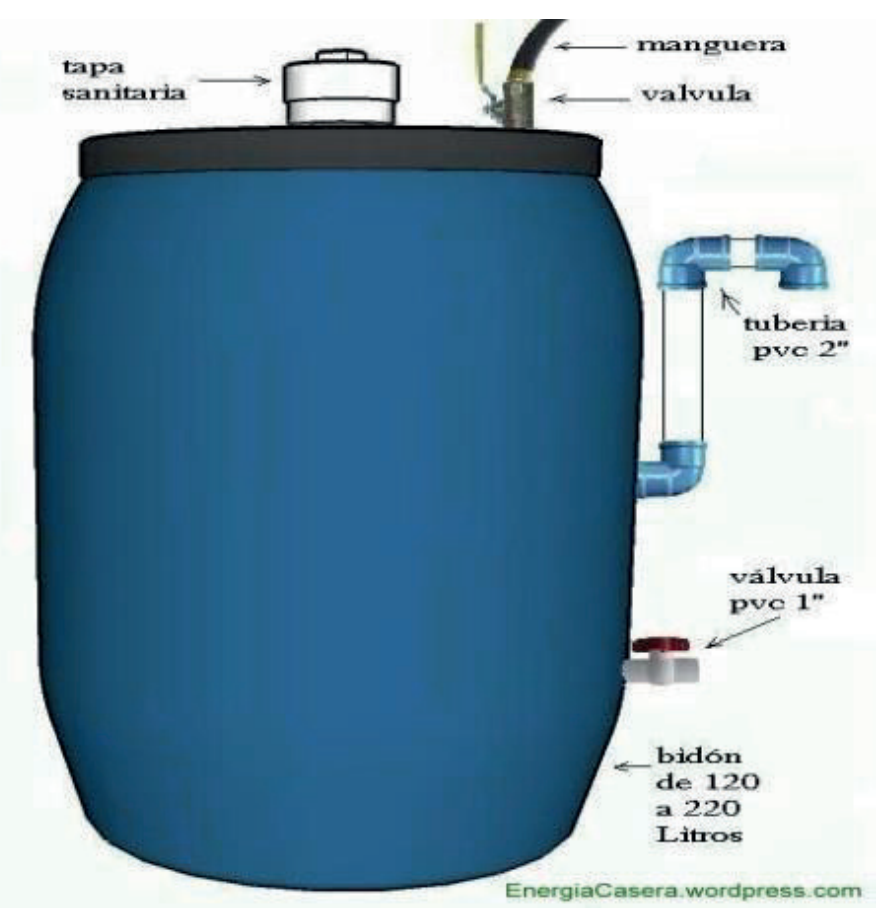

Figura 4: Sistema tipo Batch

\section{Biogás}

Según (Sandoval, 2006) el biogás es una mezcla de gases cuyos principales componentes son el metano y el bióxido de carbono, el cual se produce como resultado de la fermentación de la materia orgánica en ausencia del aire, por la acción de un grupo de microorganismos, $\mathrm{Si}$ las condiciones ambientales y operaciones son óptimas a próximamente en un período de 15 días se produce biogás.

El biogás es un gas que se genera en medios naturales o en dispositivos específicos, por las reacciones de biodegradación de la materia orgánica, mediante la acción de microorganismos (bacterias metanogénicas, etc.), y otros factores, en ausencia de oxígeno (esto es, en un ambiente anaeróbico) (Rodriguez M. , 2013). Para producir biogás es posible utilizar cualquier tipo de estiércol ya sea de vaca, cerdo, cabra, aves e incluso es posible emplear los desechos humanos (Rodriguez A., 2007). 
La FAO (2013) aporta otro concepto en el que afirma que es un gas producido por bacterias durante el proceso de biodegradación de material orgánico en condiciones anaerobias y está constituido principalmente por gas metano y bióxido de carbono. La generación natural de biogás es una parte importante del ciclo biogeoquímico del carbono. El metano producido por bacterias es el último eslabón en una cadena de microorganismos que degradan material orgánico y devuelven los productos de la descomposición al medio ambiente.

El biogás puede ser utilizado como cualquier otro combustible con poder calorífico, está en directa relación con el porcentaje de metano contenido en la mezcla, pero usualmente varía entre $16500 \mathrm{KJ} / \mathrm{Kg}$ y $21000 \mathrm{KJ} / \mathrm{Kg}$ (Valdivia, 2000).

\section{Composición del biogás}

Para analizar la propuesta del biogás se retoma la propuesta de (Lugónes, 2001), resaltando que el biogás es más liviano que el aire y está compuesto de diversos gases, los cuales se detallan en la tabla 5.

Tabla 5: Composición del Biogás

\begin{tabular}{lll}
\hline \multicolumn{1}{c}{ Gas } & & \multicolumn{1}{c}{ Contenido } \\
\hline Metano & $\mathrm{CH}_{4}$ & $54,00-70,00$ \\
Dioxido de carbono & $\mathrm{CO}_{2}$ & $27,00-45,00$ \\
Nitrógeno & $\mathrm{N}_{2}$ & $0,50-3,00$ \\
Hidrógeno & $\mathrm{H}_{2}$ & $1,00-10,00$ \\
Mnóxido de carbono & $\mathrm{CO}$ & 0,10 \\
Oxígeno & $\mathrm{O}_{2}$ & 0,10 \\
Sulfuro de hidrógeno & $\mathrm{H}_{2} \mathrm{~S}$ & 0,15 \\
\hline
\end{tabular}

Fuente: Lugones, 2001

El sulfuro de hidrógeno o ácido sulfhídrico es un gas incoloro sumamente tóxico. Es combustible y forma con el aire mezclas explosivas. Este gas posee un olor característico a huevos podridos. Este olor se percibe a baja concentración $(0,05$ hasta 500 ppm.

El problema que plantea el uso de este combustible es que contiene ácido sulfhídrico (H2S), un gas con un alto poder corrosivo que deteriora las instalaciones, por lo que es necesario eliminarlo antes de utilizar el biogás (Pohland, 1992). Actualmente existen tecnologías que permiten eliminar este ácido, mediante la combinación de procesos químicos y biológicos, en los que interviene la bacteria Thiobacillus ferrooxidans, o el uso de reactivos con FeCL3 ((Cabrera, Gómez, \& Cantero, 2005).

\section{Purificación del biogás}

En la práctica la purificación del biogás no es más que la remoción del dióxido de carbono o el sulfuro de hidrógeno o ambos. El dióxido de carbono es eliminado para aumentar el valor del biogás como combustible. El sulfuro de hidrógeno se elimina para disminuir el efecto de corrosión sobre los metales que están en contacto con el biogás. Existen varios procesos de eliminación del $\mathrm{H}_{2} \mathrm{~S}$, pero los que más se ajustan a una planta artesanal por sus costos, son procedimientos "secos". La desulfuración del biogás se basa en la reacción química de $\mathrm{H}_{2} \mathrm{~S}$ con una sustancia apropiada (Contreras, 2006).

\section{Procedimiento con cal}

(Valdivia, 2000) Describe el procedimiento de desulfuración de gases con cal viva o apagada, ya sea en forma sólida (trozos) o como solución acuosa, produce gran cantidad de residuos malolientes. Las soluciones acuosas o suspensiones de cal apagada requieren gran cantidad o despliegue de aparatos para su operación.

En presencia de grandes cantidades de $\mathrm{C}_{2} \mathrm{O}$ en el gas, como se da el caso en el biogás, es difícil lograr una eliminación satisfactoria del $\mathrm{H}_{2} \mathrm{~S} . \mathrm{C}_{2} \mathrm{O}$ también reacciona con cal viva o apagada y la consume demasiado rápido. Procedimientos utilizando masas ferrosas en forma de tierra natural o de ciertos minerales ferrosos son utilizados frecuentemente para eliminar el $\mathrm{H}_{2} \mathrm{~S}$. En este caso los contenidos de óxidos 
de hierro, en las masas ferrosas reaccionan con el $\mathrm{H}_{2} \mathrm{~S}$ obteniéndose sulfuros y agua.

También define que el principio de estos equipos de desulfuración consiste en un cajón o tonel. En su parte interior se encuentra la masa purificadora ya preparada. Esta es depositada sobre varias planchas perforadas, de manera que las capas purificadoras no sobrepasen un espesor de 20 a $30 \mathrm{~cm}$ de lo contrario la masa se comprimiría con suma facilidad, aumentando su resistencia al paso de biogás que entra en el cajón (purificador) por la parte superior, fluye a través de la masa, abandona el purificador por la parte superior ya liberada de $\mathrm{H}_{2} \mathrm{~S}$.

Una vez que la masa está saturada, esta se puede mezclar con el bioabono para que los sulfuros se trasformen en sulfatos y sean absorbidos por la tierra y podamos cerrar el ciclo.

\section{Inhibidores de la producción de biogás}

Además del amonio libre, según (García, Campos, Dalmau, Illá, \& Sanchez, 2006), el sulfonato linear del alquilbenceno (LAS) es el surfactante aniónico más importante en agentes limpiadores de hogares e industrias. En la mayoría de los digestores, la adición de surfactantes causa una disminución de la tasa de producción de biogás. Esto debe ser tomado en cuenta a la hora de adicionar residuos domésticos e industriales a un biodigestor en funcionamiento, ya que la productividad, lejos de aumentar se podría ver afectada. Los pesticidas, desinfectantes o antibióticos presentes en algunos residuos también pueden llegar a afectar el proceso según su concentración.

\section{Usos del Biogás}

A pequeña y mediana escala, el biogás ha sido utilizado en la mayor parte de los casos para cocinar en combustión directa, sin embargo, también puede ser utilizado para iluminación, calefacción, como reemplazo de la gasolina o el diésel en motores de combustión interna, operar maquinaria agrícola o bombear agua. Este tiene un poder calorífico por lo general entre 50 y $70 \%$ del gas natural. Se debe tener especial cuidado con el ácido sulfhídrico del biogás, ya que ocasiona corrosión prematura en los equipos, por esta razón es necesario colocar una trampa de limadura de hierro en la línea de transporte del biogás (Valdivia, 2000).

\section{CONCLUSIONES}

El biogás es un recurso energético que constituye una opción hacia la transición energética, ya que puede ser empleado como combustible para generar electricidad, calor y/o energía mecánica a partir de una fuente renovable como lo son los cultivos energéticos, o bien a través de residuos agropecuarios, agroindustriales y municipales, entre otros. Por otra parte, desempeña un papel importante en la mitigación de gases de efecto invernadero.

El análisis de la distribución de las fuentes potenciales para la producción de biogás provenientes del sector ganadero, rellenos sanitarios y plantas de tratamiento es compleja y está relacionada con otros factores (sociales, desarrollo científico, disponibilidad de la tecnología, etc.). Decir que estos resultados son concretos es inverosímil. Sin embargo, son un panorama preliminar que permite visualizar los nichos de oportunidad para la producción de biogás. Los desechos sólidos (altos en contenido de materia orgánica) no deberían ser considerados como un problema, sino como una oportunidad para la generación de una fuente renovable de energía y una medida efectiva para la mitigación de gases de efecto invernadero.

La promoción y difusión de las tecnologías para su aprovechamiento son necesarias para que la sociedad se involu $\neg$ cre en el beneficio que tiene el aprovechar los desechos en la producción de energía y en la contribución a la disminución de la contaminación ambiental. 
Existe diversidad de literatura sobre el tema de estudio sobre el cual se ha recogido información y me es posible afirmar que existe información de todo tipo y con diferente nivel científico por lo cual al realizar mi tesis doctoral considero no tendré inconvenientes respecto a la literatura existente para el abordaje de mi tesis. Soy consciente que la autenticidad está determinada por el nivel de correspondencia con las exigencias epistemológicas, sociales, culturales, axiológicas, etc, existentes en el momento de recogida de la información $\mathrm{y}$ en situaciones presentadas sean estas de cualquier orden. Existe la posibilidad como todo de que mi tema quizás resulte auténtico en unas circunstancias y en otras deje de serlo, aunque tal vez pueda mantener su relativa novedad.

Es importante considerar que el desarrollo tecnológico de cualquier nación incluyendo la nuestra debe estar asentada en bases científicas sólidas, y orientarse hacia unas formas de producción limpias y sin riesgos, una utilización de los recursos más eficiente, en el cual el producto final sea más respetuoso conel medioambiente.

\section{BIBLIOGRAFÍA}

Ahring, B. K., Sandberg, M., \& Angelidaki, I. (1995). Volatile fatty acids as indicators of process imbalance in anaerobic digester. Applied microbiological biotechnology(43), 559-165.

Alcántara, A. F. (1993). Residuos Agrícolas, forestales, ganaderos e industriales. Málaga, España: Instituto de Investigaciones Ecológicas.

Arthur, R., Baído, F., \& Antwi, E. (2011). Biogás as potential renewable energy source. Renewable Energy, 36, 1510-1516.

Asofénix. (2008). Instalación de Biodigestores en Comunidades de Teustepe y San Jose de los Remates. Managua : Asofenix. Recuperado el Mayo de 2016

Bernal, M. P., \& Roig, A. (1993). Nitrogen transformations in calcareous soils amended with pig slurry under aerobic incubation. Agric. Sci(120), 89-97.

Bidlingmaier, W. (2006). Probes anaerobic digestion. Biocicle journal of composting and organics recy- $\operatorname{clin}(47), 42-49$.

Boone, D. R., \& Xun, L. (1987). Efeccts of pH, temperature and nutrients on propionate degradation by methanogenic enrichment culture. Appied and enviromental microbiology(53), 1589-1592.

Borroto Nordelo, A. (2002). Los sistemas energéticos y sus costos ambientales. Cienfuegos: Universidad Cienfuegos.

Botero, R., \& Preston, T. (1987). Biodigestor de bajo costo para la producción de combustible y fertilizante a partir de excretas. Calí, Colombia: CIPAV. Boyle, G. (2004). Renewable Energy. New york: Oxfor University Press.

Brambilla, M., Araldi, F., Marchesi, M., Bertazzoni, B., Zagni, M., \& Navarotto, P. (2012). Monitoring of the startup phase of one continuous anaerobic digester at pilot scale level. Biomass and Bioener$g y(36), 439-446$.

Bunca . (2002). Fortalecimiento para la capacidad en energias Renovables. Manuales sobre energía renovable . Biomasa. San Jose, Costa Rica: Bunca CA. San Jose, Costa Rica .

Cabrera, G., Gómez, J. M., \& Cantero, D. (2005). Influence of heavy metals over growth and ferrous sulphate oxidation by acidithiobacilus ferroxidans in pure and mixed cultures. Process Biochemis$\operatorname{try}(40), 683-2687$.

Camilo, C., Ann, C., \& Wilkie, D. (2010). Greenhouse gas emission and biogas potential from livestock in Ecuador. Energy for sustainable development, 14, 256-266.

Campos Pozuelo, A. E. (2001). Optimización de la digestión anaerobia de purines de cerdo mediante codigestion con residuos organicos de la industria agroalimentaria. Lleida, España. Recuperado el 10 de Mayo de 2017, de http://www.tesisenred.net/ bitstream/handle/10803/8229/Tecp1de1.pdf?sequence $=1$

Carreras, N., \& Dorronsoro, J. L. (1999). Aprovechamiento energético de los residuos sólidos urbanos (RSU) en España. Residuos(50), 66-68.

Chugh, S., Chynoweth, D. P., Clarke, W., Pullammanappallil, P., \& Rudolph, V. (1999). Degradation 
of unsorted municipal solid waste by a leach bed process. Bioresource Technology(69), 103-115.

Chynoweth, D. P. (1996). Enviromental inpact of biomethanogenesis. Envir Monitoring and Assessment(42), 3-18.

Chynoweth, D. P., \& Isaacson, R. (1987). Digestión anaerobica de la biomasa. Elsevier Applied Science, 1-15.

Clark, R. H., \& Speece, R. E. (1989). The pH tolerance of anaerobic digestion. Advanced water pollution research, (págs. 14-27).

Contreras. (2006). Digestión anaerobia para el tratameinto de residuos orgánicos. El caso de Perú. Barcelona, España: Escuela Técnica de ingeniería Industrial.

Contreras, L. (2006). Producción de biogás con fines energéticos. De lo histórico a lo estratégico.

De Baere, L. (2000). Anaerobic Digestion of Solid Waste: State of the art. Aater Science Technolo$g y(41), 283-290$.

Dorronsoro, J. L., \& Carreras, N. (1999). Aprovechamiento energético del biogás generado a partir de residuos solidos urbanos. Tecnoambiente(71), 121-123.

Drake, H. L., Kusel, K., \& Matthies, C. (2002). Ecological consequences of the phylogenetic and physiological diversities of acetogens.

Dutta, S., \& Rehman, P. (1997). Biogás: The indian NGO experience. New Delhi.

Eastman, J., \& Ferguson, J. (1981). Solubilization of particulate organic carbon during the acid phase anaerobic digestion. Wat Pollut Control Fed(53), 352-366.

Echaendia, A., \& Menoyo, A. (1990). Compostaje de Gallinaza en un sistema dinamico abierto. Congreo Internacional de Química (págs. 431-438). Tenerife: ANQUE.

EREC. (2009). Renewable energy policy review. Sweden.

Estrada Pareja, M. M. (Enero-junio de 2005). Manejo y procesamiento de la gallinaza. Revista Lasallista de Investigación, 2(1), 43-48.

Fan, L., Chen, L., Mehta, C., \& Chen, Y. (1985). Ener- gy and availabre energy contents of cattle manure and digester sludge. Agricultural Wastes(13), 239249.

FAO. (2013). Produccíon de biogas por metanogénesis. Aprobechamiento de residuos sólidos, 42-47. Recuperado el 5 de Mayo de 2016

Flotats, X., Bonmatí, A., Campos, E., \& Teira, M. R. (2000). El proceso de secado de purines en el marco de gestión integral de residuos ganaderos. Residuos(53), 40-56.

Gallert, C., Bauer, S., \& Winter, j. (1998). Effect of ammonia on anaerobic degradation of protein by a mesophilic and thermophilic biowaste population. Microbiology and Biotechnology(50), 495-501.

Gao, K., \& Mckinley, K. (1993). Use of macroalgae for marine biomass production and $\mathrm{CO} 2$ remediation. a review J. of App Phycology(6), 45-60.

García Garrido, S. (2009). Centrales Termoeléctricas de Biomasa. Madrid: RENOVETEC.

García Gutíerrez, G. d., Mondaca Fernández, I., Meza Montenegro, M. M., Fuentes, A. F., Balledera Córtez, J. d., \& Gortarez Moroyoqui, P. (Julio de 2012). Ideas@CONCYTEG. Obtenido de http://www. concyteg.gob.mx/ideasConcyteg/Archivos/85_1_ GUTIERREZ_GARCIA_ET_AL.pdf

García, M. T., Campos, E., Dalmau, M., Illá, P., \& Sanchez, J. (2006). Inhibition of biogas production by alkyl benzene sulfonates in a screenig test for anaerobic biodegradability. Biodegradation, 17, 3946.

García, P. S. (2006). La biomasa y la energía. México DF .

Garrido, J. M., Flotats, X., Fernández, B., \& Palatsi, J. (2009). Biomasa (Tercera ed.). Barcelona, España: UPC.

Gerardi, H. (2003). Upsets and Unstable Digester in the Microbiology of Anaerobic Digester. New Jersey, USA: Hoboken.

Han, J. L. (2008). Small scale fuel wood project in rural china. Energy Polici, 36, 2154-2162.

Hashimoto, A. G. (1986). Ammonia inhibition of methanogenesis from cattle wastes. Agricultural Waste(17), 241-261. 
Hashimoto, A., \& Chen, Y. (1982). methane from cattle wastes: effects of temperature, hidraulic retention time and influent substrate concentration on kinetic parameter (K). Biotech Bioeng(24), 2039-2052.

Henze, M. (1995). Wastewater, volumes and composition: Biological and chemical process. Springer.

Hilbert., J. A. (2007). Manual para la producción de biogás. México DF: Castelar .

Hobson, P. N. (1995). The treatment of agricultural wastes, en anaerobic digestion: a waste treatment technolgy. Critical reports on applied chemistry, $31,121$.

Hwu, C. H., \& lettinga, G. (1997). Acute toxicity of oleate to acetate utilizing methamogens in mesophilic and temperature anaerobic sludge. Enzyme microbiology Technologt(21), 297-301.

IDAE. (2007). Biomasa: Digestores anaerobios. Madrid.

Jarauta, L. (2005). Digestión anaerobia para el tratameinto de residuos orgánicos. El caso de Perú. Barcelona, España: Escuela Técnica de ingeniería Industrial.

Kennedy, J. K., \& Berg, D. V. (1982). Anaerobic digestion of piggery waste usin a stationary fixed film reactor. Agric Wastes(4), 151-158.

Klinger, I., Alexander, R., \& Marchaim, U. (1991). A suggested solution for slaughterhouse wastes: Uses of the residual materials after anaerobic digestion. Bioresource Technology(37), 127-134.

Krugel, S., Nemeth, L., \& Peddie, C. (1998). Extending thermophilic anaerobic digestion for producing class a biosolods at the greater Vancouver regional districts annacis island wastewater treatment plant. Water Science and Technology(38), 409-416.

Lay, J. J., Li, Y. Y., \& Noike, T. (1997). Influences of pH and moisture content on the methane production in high solids sludge digestion. Water Research(31), 1518-1524.

Lissens, G., Vandervivere, P., De Baere, L., Bley, E. M., \& Verstraete, W. (2001). Solid waste digester. Water Science Technology(44), 91-102.

Lockett, W. (1997). Digestores de gas metano para obtener combustibles. The new alchemy institute west.

Lugónes, B. (2001). Analisis de biodigestores en funcionamiento . Habana, Cuba.

Madigan, M. T., Martinko, J. M., \& Parker, J. (1998). Brock Biology of microoganisms (Octava ed.). Prentice May International.

Mara, D., \& Horan, N. J. (2003). The handbook of water and waster microbiology. Academy Press.

Marchaim, U. (1992). Biogás processes for sustainable development. Food and Agriculture Organization of the United Nations (FAO). FAO Agricultural Service Bulletin.

Massoud, M., \& El-Fadel, M. (2001). Methane emissions from wastewater management. Enviromental Pollution(114), 177-185.

Mata Álvarez, J., Macé, S., \& Llabrés, P. (2000). Anaerobic of organic solid wastes. An overiew of research achievements and perspectives. Bioresource Technology(74), 3-16.

Mathieu, L. (2014). Biomasa Clasificación y uso. En Aplicaciones de la Biomasa. Madrid, España.

Metcalf, \& Eddy. (1994). Ingeniería sanitaria: tratamiento, evacuación y reutilización de aguas residuales (Tercera ed.). Colobia: McGraw Hill.

Mihelcic, J., \& Zimmerman, J. (2011). Ingeniería Ambiental: fundamentos, sustentabilidad, diseño. México: Alfaomega.

Milan, Z., Sánchez, E., Weiland, P., Borja, R., Martín, A., \& llangovan, K. (2001). Influence of diferent natural zeolite concentrations on the anaerobic digestion of piggery waste. Bioresource Technolo$g y(80), 37-43$.

Miranda, H. (2007). Biogas: Substratos, desarrollo de la técnica y costos. Alemania: UTEC.

Muller, V. (2003). Energy conservation in acetogenic bacteria.

NOM-010-STPS. (1999). Condiciones de seguridad e higiene en los centros de trabjo donde se manejen, transporten, procesen o almacenen sustancias químicas capaces de generar contaminación en el medio ambiente laboral.

Nopharatana, A., Pullammanappallil, P. C., \& Clarke, W. (2003). A dynamic mathematical model for se- 
quencial leach bed anaerobic digestion of organic fraction of municipal solid waste. Biochemical Engineering Journal(13), 21-33.

Ortiz, J., \& Aguila, L. (1997). La depuración biológica de efluentes industriales. Ingeniería Química(29), 147-153.

Osorio, J., Ciro, H., \& Gonzalez, H. (2007). Evaluación de un sistema de biodigestión en serie para clima frío. Rev. Fac. Nal. Agr(2), 60.

Parr, J. F., \& Colacicco, D. (1987). Organic materials as alternative nutrient sources. En Energy in plant nutrition and pest control (págs. 81-89).

Pavlostathis, S. G., \& Giraldo Gómez, E. (1991). Kinetics of anaerobics treatment: a critical review. Critical reviews in enviromental control(2), 490.

Peece, R. E. (1983). Biotechnology for anaerobic waste treatment. Science and Technology(17), 416A - 427A.

Poeschl, M., Ward, S., \& Owende, P. (2010). Prospect for expanded utilization of biogas in Germany. Renewable and Sustainable Energy Review, 14, 17821797.

Pohland, F. G. (1992). Diseño de procesos anaerobicos para el tratamiento de residuos industriales y municipales (Vol. 7). Landcaster P.A.

Ramírez, G. (1983). Compostaje y uso de residuos orgánicos en Costa Rica. Roma, Italia: FAO.

Rodriguez, M. (2013). Historia del biogás, primeros pasos. Ciencia y sociedad, 72-77.

Sandoval, A. (2006). Manual de tecnologías limpias en Pymes. Perú .

Schink, B. (1997). Energetic of syntrophic cooperation in methanogenic degradation. Microbiol(61), 262280.

Schink, B. (1997). Energetics of Syntrophic Cooperation in Methanogenic Degradation. Microbiology and Molecular Biology(2), 262-280. Recuperado el 10 de Mayo de 2017

Schwartz, H., \& Jacobs, J. (1984). Sociología cualitativa. Método para la reconstrucción de la realidad. Mexico DF: Trillas.

Sikes, R. M. (1975). Theoretical heterotrophic yields.
Control Fed(47), 591-600.

Sinh, R. B. (1974). The biogas plant. generating mehane from organic wastes. UP.

Sogari, N. (2003). Cálculo de la producción de metano generado por distintos restos orgánicos. Argentina: Comunicaciones científicas y tecnológicas.

Stafford, D. A. (1982). the effects of mixing and fatty acid concentration on anaerobic dogester performance. Biomass(II), 43-55.

Stams, M. (1994). Metabolic interactions between anaerobic bacteria in methanogenic environments. (66), 271-294.

Tchobanoglous, G., Hilary, T., \& Vigil, S. (1997). Gestión integral de residuos sólidos. McGraw Hill.

Turner, C., \& Burton, C. H. (Technology). The inactivation of viruses in pig slurries: a review. Bioresource(61), 9-20.

Valdivia, T. R. (2000). Uso de Biogás para la generación de energía eléctrica mediante un motor gasolinero estacionario modificado. Lima, Perú.

Valencia, D., \& Ramírez, M. (2009). la industria de la leche y la contaminación del agua. Elementos(73), 27-31.

Van Lier, J. B., Hulsbeek, J., Stams, A. J., \& Lettinga, G. (1993). Temperature susceptibility of thermophilic methanogenic: implication for reactor startup and operation. Bioresource Technology(43), 227-235.

Viñas, M. (1994). Criterios de diseño y escalado de reactores anaerobios. Montevideo, Uruguay.

Vogt, G. M., Liu, H. W., Kennedy, K. J., Vogt, H. S., \& Holbein, B. E. (2002). Super blue box reycling (SUBBOR) enhanced two satage. Anaerobic digestion process for recycling municipal solid waste: Laboratory pilot studies. Bioresource Technolo$g y(85), 291-299$.

Werner, E. (1983). Bioconversión: producción de energía utilizando desperdicios agricolas (Primera ed.). La Paz, Bolivia.

Zeikus, J. L. (1979). Thermophilic bacteria: Ecology, physiology and technology. Enzyme and Microbial Technology(4), 243-252. 